Article

\title{
Operational Hydrological Modelling of Small Watershed using QPE from Dual-Pol Radar in Brazil
}

\author{
Cesar Beneti ${ }^{1, \ddagger}$, Roberto V. Calheiros ${ }^{1, \ddagger}$, Mino Sorribas ${ }^{1, \ddagger}$, Leonardo Calvetti ${ }^{2, \ddagger}$, Camila Oliveira \\ 1, $\ddagger$, Nicole Rozin ${ }^{1, \ddagger}$, and Jorge Ruviaro ${ }^{1, \ddagger *}$ \\ 1 SIMEPAR - Parana Meteorological Service, Curitiba, Brazil; cesar.beneti@simepar.br \\ 2 UFPEL - Federal University of Pelotas, Pelotas, Brazil, 2; lcalvetti@gmail.com \\ * Correspondence: cesar.beneti@simepar.br; Tel.: (+55-41-3320-2002; (F.L.) \\ $\ddagger \quad$ These authors contributed equally to this work.
}

\begin{abstract}
Among other applications, radar-rainfall (RR) and QPE (Quantitative Precipitation Estimation) based on radar reflectivity, dual polarization variables, and multi-sensor information, provide important information for land surface hydrology, such as flood $f$ orecasting. Therefore, we developed a flood a lert s ystem $u$ sing $r$ ainfall-runoff $m$ odel $f$ orced $w$ ith $R \mathrm{R}$ a nd Q PE, and tipping-bucket observations to forecast river water levels (using rating-curves). In this study, we used an hourly dataset from an S-Band dual-polarimetric radar with two tropical $R(Z)$ relations based distrometer data, a polarimetric R(Z,ZDR) algorithm from the literature and a multi-sensor approach using radar, satellite and rain gauge. Two hydrological models were used and calibrated using observed discharge time-series. Although our previous studies indicated accurate RR-based simulations, in some cases floods were not detected when using catchment-lumped rainfall derived from multi-sensor QPE. In this study, we advance further in this subject using improved R(Z,ZDR) relations and QPE for the period of 2016-2017 and flood event-based rainfall-runoff calibration. Thus, we focused on the development (and timing) of floods in the Marrecas River can be complex and strongly related to storms spatiotemporal distribution. To explore this aspect, we also perform a first analysis in using RR in rainfall-runoff model with a nested catchment discretization.
\end{abstract}

Keywords: Weather Radar; Quantitative Precipitation Estimation; Remote Sensing; Hydrological Applications

\section{Introduction}

Improved rainfall estimates enhance the potential of radar for many applications such as flood forecasting and management of hydro power generation. In less than 5 years, in Brazil we increased our radar coverage, from 23 single polarization radars to 15 additional dual polarization radars, mainly S-Band, with a concentration in the southern region, an area prone to severe weather, usually related to mesoscale convective systems. This region is responsible for more than $35 \%$ of the national hydro power energy generation, directly dependent on precipitation distribution and water availability, and storm events result in disasters related to flood inundation. Polarimetric techniques, which undergo an ever-growing implementation, carry the promise of providing rainfall estimates which are significantly more accurate than those derived from single polarization measurements.

A better representation of rainfall spatial distribution and its uncertainties is crucial for accurate forecasts of river discharges and water levels. Radar estimations of QPE (Quantitative Precipitation Estimation) are very useful information for hydrological applications because of high spatial and temporal resolution improving runoff forecasts and reducing model dependence on unreliable parameter estimates of watershed characteristics. However, radar QPE depends on the calibration, 


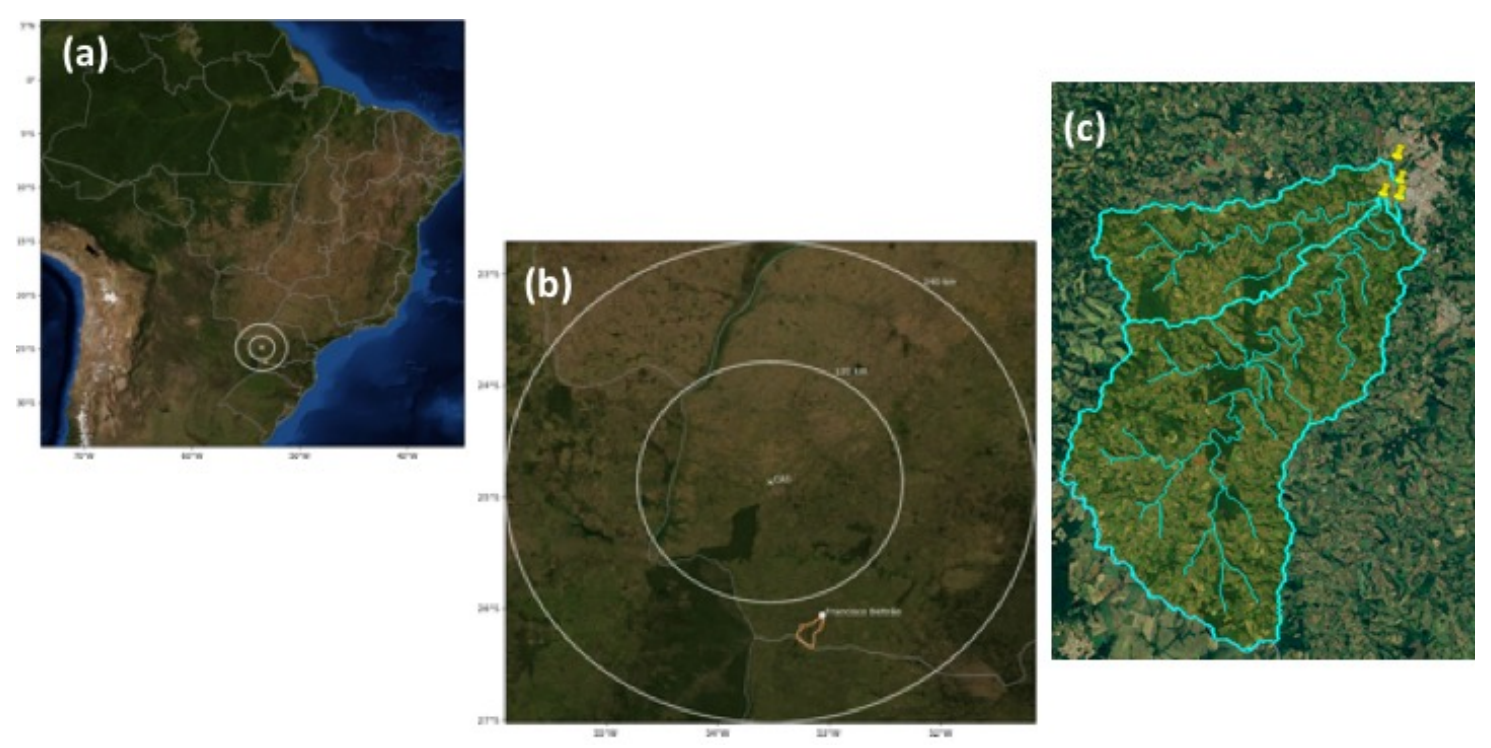

Figure 1. (a) Radar and basin location in South America; (b) Marrecas river basin in radar range and Francisco Beltrao city; (c) Marrecas river basin and rain gauges (yellow markers.

good adjustment with rain gauges and distrometers, data filtering, distance from the radar, orography, signal propagation, among other factors. A multi-sensor integration approach of remote sensing precipitation estimation using meteorological satellites and weather radars with rain gauges improves the accuracy of hydrological models when compared to a model using gauge data only.

\subsection{Study area}

In this study, we have selected the Marrecas River catchment to evaluate the performance of quantitative precipitation estimates for in rainfall-runoff modeling. The Marrecas River flows in a mostly rural catchment until it enters the city of Francisco Beltrao where it is channelized. Figure 1 presents the area of the catchment in the region. Near the urbanized area, it also receives a major contribution from the Quatorze River, but there are no water level gauges installed in this tributary. The city of Francisco Beltrao grew up beside the Marrecas River and have suffered with occasional inundations due to its major floods.

Over the last 25 years, these floods caused almost 0.5 billion US Dollars in property and crop losses. Between 2013 and 2015, three events were recorded bringing great injuries to local properties. In recent years, river floods resulted in economic damages related to overbank inundation but also due to restrictions in the water supply operation during floods. In fact, a recent rainfall event during early November 2017 resulted in a flooding event with peak flow about $230 \mathrm{~m}^{3} / \mathrm{s}$ ( 10 years return period) with a rising limb developing in 2 days (Figure 2).

The watershed area is $335 \mathrm{~km}^{2}$ and the fast rainfall-runoff response time, between the rainfall and river flow peaks is between 12 to 24 hours. But, larger floods can have full development up to $2-5$ days. The hydrological network is sparse in the region with rain gauges outside the catchment. Because of such characteristics, an early warning system is vital to prevent even bigger losses.

\section{Methodology}

In this study, we evaluate the use of rainfall estimates retrieved from radar, multisensor QPE product [1] and tipping-bucket observations in the simulation of a rainfall-runoff at a $335 \mathrm{~km}^{2}$ river catchment. We used a limited dataset from a S-Band dual polarimetric radar with tropical $R(Z)$ relations based on distrometer data and a polarimetric R(Z,ZDR) and R(Z,KDP) algorithm, following Crisologo et al. [2]. Figures 3 and 4 present sample cases of precipitation estimation with the multisensor QPE product (SIPREC)as well as the polarimetric rainfall estimation obtained from the S-Band and also a 


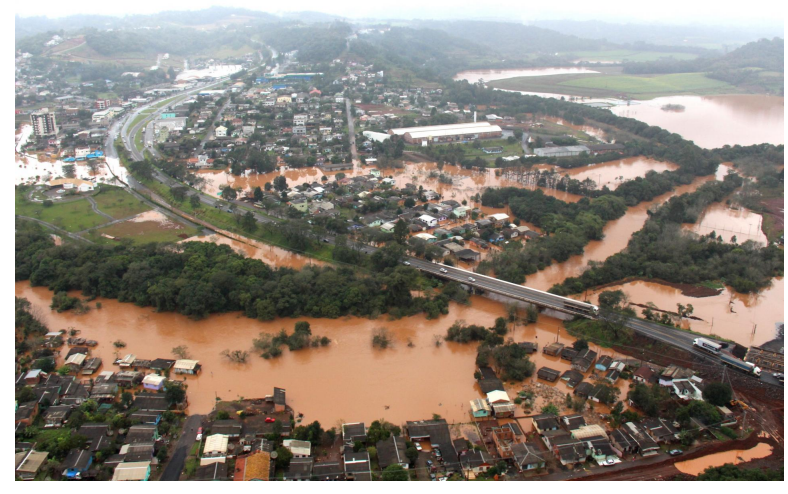

Figure 2. Flooding in Francisco Beltrao city in November, 2017.

distrometric relation for the region of the events. Those accumulations were integrated throughout 2 days during the period of study. The rainfall estimation from the polarimetric weather radar will be used to evaluate the impact of radar data in river basin in Brazil.

At present, various hydrological models have been developed and widely used in water resources planning and flood forecasting. Each model has its specific conceptual formulation, thus the capability to reproduce aspects of the real world depends on the underlying assumptions, but also in input and output measurements that sets model forcing, boundary and initial conditions. The areal precipitation is the dominant input for rainfall-runoff models and is often estimated from interpolation of rain gauge data, derived from remote sensors and radars.

Model performance was assessed for flood events in years 2016 and 2017 (verification and calibration). Hourly data of rainfall and streamflow were used for model calibration using the Multi-objective Complex Evolution (MOCOM-UA, [3]). In the multi-objective approach,parameter optimization was defined towards a trade-off between the KGE ([4]), logNS (Nash-Sutcliffe of log-transformed discharges) and (error in volume). Finally, other statistics such as Nash-Sutcliff (NS), pearson correlation and RMSE were also evaluated. In order to reduce the sensitivity to initial state variables a dry warm-up period was used and not considered in the model calibration.

Two hydrologic models were selected for this study including the Sacramento Soil Moisture-Accounting model (SAC-SMA, [5]; [6]) and the Brazilian SMAP (Soil-Moisture Accounting Procedure, ([7]). These are nonlinear, time-continuous and conceptual rainfall-runoff models, requiring inputs of precipitation and potential evapotranspiration (i.e. Penman-Monteith). The SMAP model is based on the USGS SCS TR-55 model accounting for water balance dynamics and uses tank models for catchment/river routing. The hydrologic models were forced with three different rainfall estimates retrieved from radar, tipping-bucket observations and multi-sensor QPE [1]. The SAC-SMA is known to be used operationally for flood forecasting by several weather services including the United States of America. At SIMEPAR, both SAC-SMA and SMAP are operational for flood warning and hydropower operation systems. Nevertheless, the ONS (Operador Nacional do Sistema Eletrico Brasileiro) uses the SMAP model (and adaptations) to support short-range energy planning in many brazilian watersheds.

\section{Results}

The rainfall-runoff model performance for SAC-SMA and SMAP for the flood events of nov/2017 are summarized in the Table 1. Hence, it was possible to reproduce the large floods with both hydrological models and the four different rainfall estimates. The correlations between observed and simulated discharges was high, in most cases larger than 0.75, and RMSE in the range of 15 and 35 $\mathrm{m}^{3} / \mathrm{s}$ is low when compared to flood peaks of $200 \mathrm{~m}^{3} / \mathrm{s}$ (return period of 5 years). For the SAC-SMA model simulations the KGE values were mostly between $0.50-0.82$ with rainfall retrieved from radar; and 0.93 for the raingauge. In general, model performance was satisfactory for the SAC-SMA and best simulations with rain gauge, $\mathrm{R}(\mathrm{Z}, \mathrm{ZDR})$ and SIPREC. The results for the SMAP model were also in 
[a]
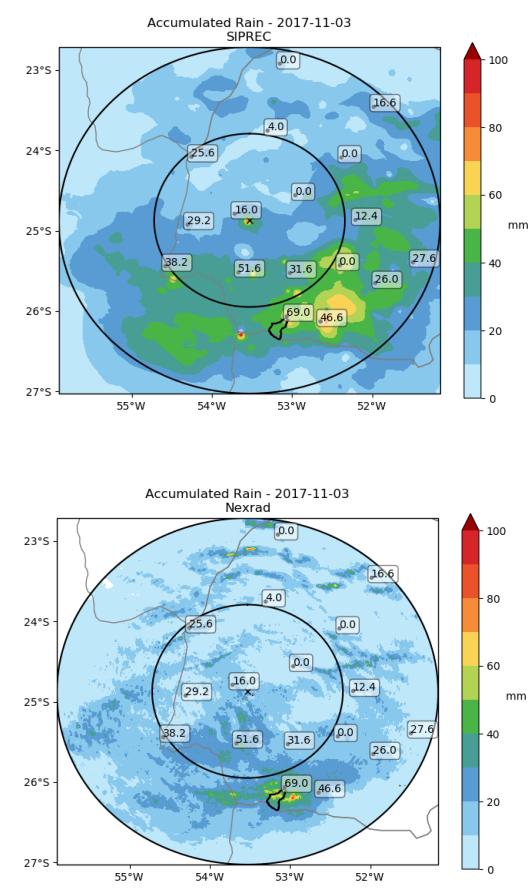

[c]

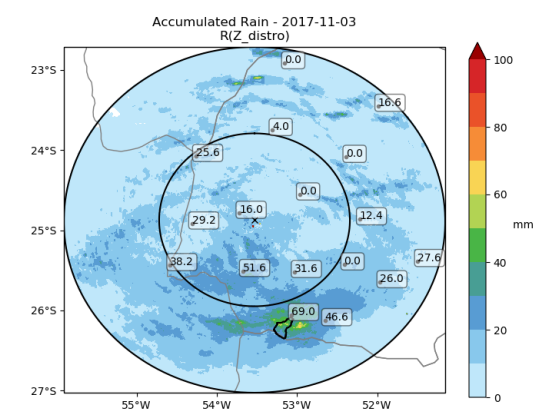

[e]

Figure 3. Precipitation estimation in the radar and basin area compared with raingauge daily rainfall accumulation. (a) and (b): Mulsisensor QPE (Calvetti etal 2017); (c) and (d): NEXRAD tropical Z-R; (e) and (f): Distrometric Z-R relationship (Calheiros et al 2018). [b]
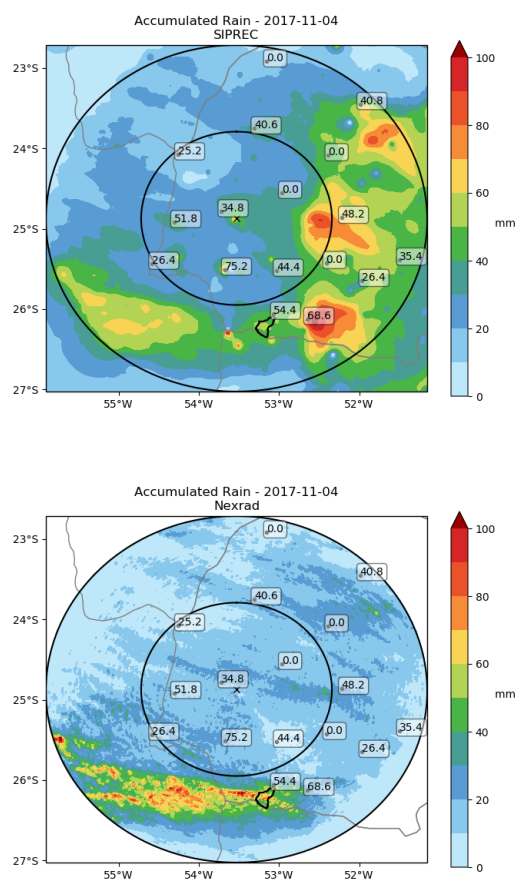

[d]

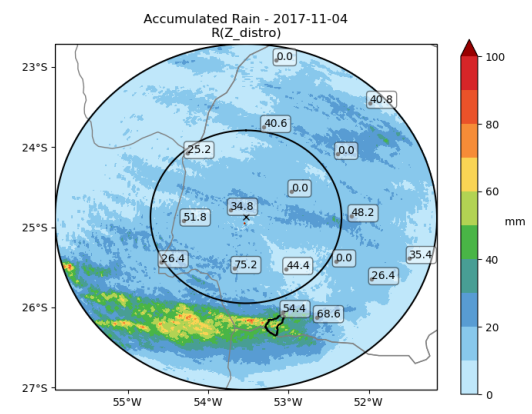

[f] 


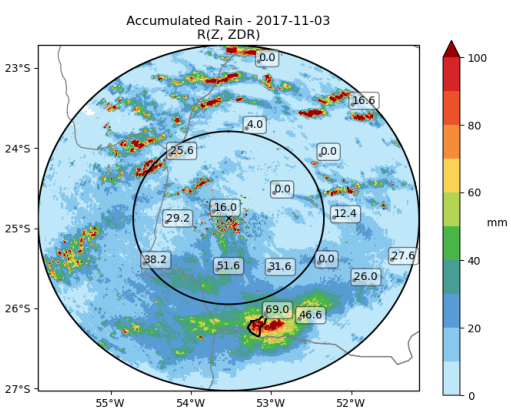

[a]

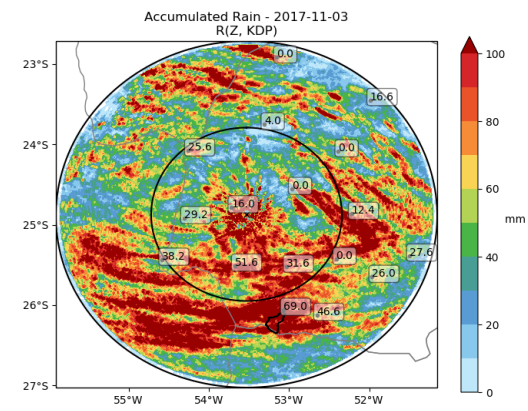

[C]

Figure 4. Precipitation estimation in the radar and basin area compared with raingauge daily rainfall accumulation. (a) and (b): Polarimetriz R(Z,ZDR); and c) and (d): Polarimetric R(Z,KDP).

98

99 for R(disdro) and SIPREC than for rain gauge.

Table 1. Rainfall-runoff model performance for SAC-SMA and SMAP - flood events in nov/2017

\begin{tabular}{|c|c|c|c|c|c|c|c|}
\hline Forcing & Model & KGE & $\Delta \mathrm{V}\left({ }^{*} 1 \mathrm{e} 2 \%\right)$ & NS & logNS & PEARSON & RMSE \\
\hline \multirow{2}{*}{ Raingauge } & $S A C-S M A$ & 0.93 & 0.01 & 0.87 & 0.80 & 0.93 & 17.64 \\
\cline { 2 - 8 } & $S M A P$ & 0.91 & 0.00 & 0.82 & 0.73 & 0.91 & 20.50 \\
\hline \multirow{2}{*}{ R(Z.ZDR) } & $S A C-S M A$ & 0.82 & 0.02 & 0.66 & 0.68 & 0.82 & 28.68 \\
\cline { 2 - 8 } & $S M A P$ & 0.75 & 0.01 & 0.51 & 0.66 & 0.75 & 34.08 \\
\hline \multirow{2}{*}{ R $_{\text {distro }}$} & $S A C-S M A$ & 0.51 & 0.03 & 0.56 & 0.13 & 0.78 & 32.42 \\
\cline { 2 - 8 } & $S M A P$ & 0.94 & 0.00 & 0.89 & 0.83 & 0.94 & 16.48 \\
\hline \multirow{2}{*}{ SIPREC } & $S A C-S M A$ & 0.71 & 0.00 & 0.69 & 0.29 & 0.83 & 27.19 \\
\cline { 2 - 8 } & $S M A P$ & 0.94 & 0.00 & 0.88 & 0.81 & 0.94 & 17.21 \\
\hline
\end{tabular}

Figures 5 and 6 show the observed discharges and simulation results from SMAP and SAC-SMA model runs for a sequence of major flood events during oct-nov/2017. For the SAC-SMA model, it is also possible to verify a good agreement in simulations, although in this case R(Z,ZDR) and raingauge were more reliable. The SMAP was able to reproduce the peak of the two major flood events. It was also possible to see that R(disdro) and SIPREC were in better agreements with the smaller floods. The $100 \mathrm{~m}^{3} / \mathrm{s}$ flood in the beginning of oct/16 clearly illustrates uncertainty related to different combinations of rainfall inputs and models.

[b]
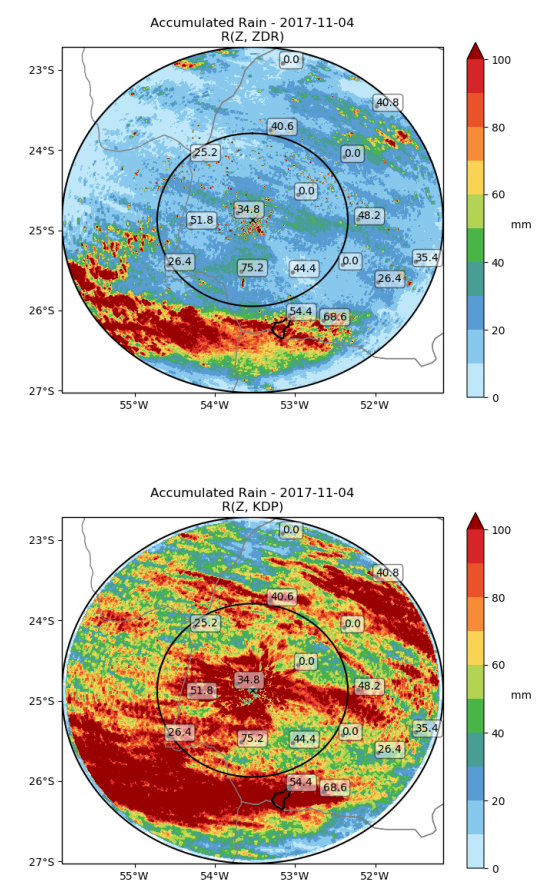

[d] 


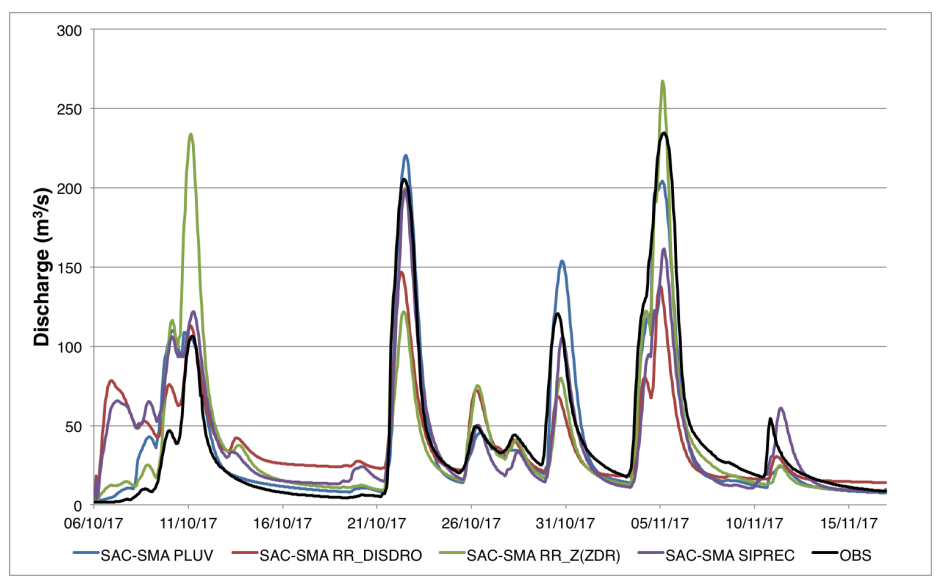

Figure 5. Simulated discharges for flood events in november 2017 with the SAC-SMA model and different QPE

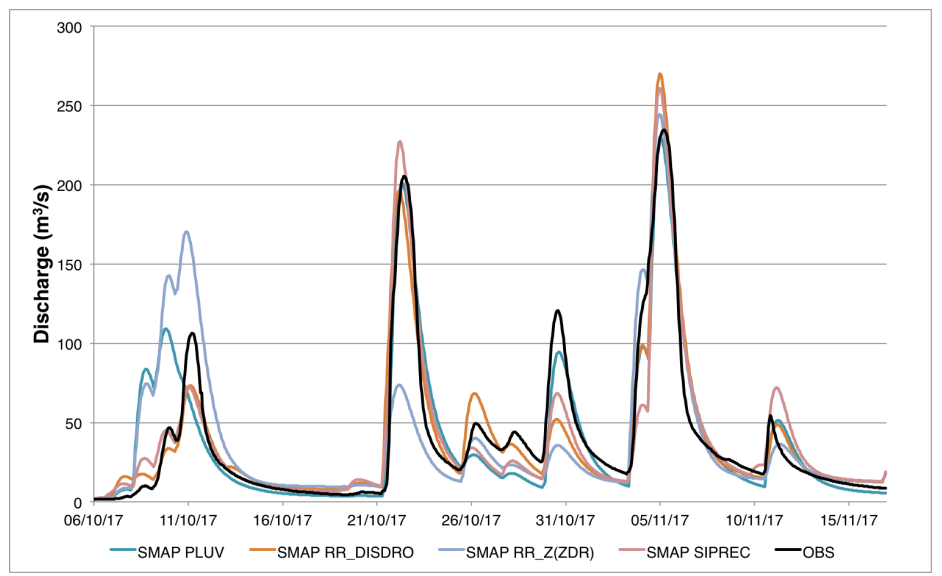

Figure 6. Simulated discharges for flood events in november 2017 with the SMAP model and different QPE

The rainfall-runoff model performance for SAC-SMA and SMAP for the flood events of oct/2017 are summarized in the Table 2. Correlations between observed and simulated discharges was high (>0.71) and RMSE in the range of $15-44 \mathrm{~m}^{3} / \mathrm{s}$, large in relation to the flood peak of $100 \mathrm{~m}^{3} / \mathrm{s}$. For this case, most of the statistics were not satisfactory for this event, as a result from overestimation of discharges. There is general trend in the formation of two convoluted floods in the first days of model runs, associated with rainfall estimates that did not result in real increase of the water level. However, SAC-SMA performed well for rain gauge and R(Z,ZDR) with KGE(NS) of $0.77(0.81)$. The SMAP model also showed a good agreement for R(Z,ZDR) with KGE(NS) value of $0.68(0.53)$. Figures 7 and 8 illustrates results for model runs for the oct $/ 2016$ flood events.

Table 2. Rainfall-runoff model performance for SAC-SMA and SMAP - flood event in oct/2016

\begin{tabular}{|c|c|c|c|c|c|c|c|}
\hline Forcing & Model & KGE & $\Delta \mathrm{V}\left({ }^{*} 1 \mathrm{e} 2 \%\right)$ & NS & logNS & PEARSON & RMSE \\
\hline \multirow{2}{*}{ Raingauge } & $S A C-S M A$ & 0.77 & 0.11 & 0.59 & 0.75 & 0.81 & 11.97 \\
\cline { 2 - 8 } & $S M A P$ & -0.43 & 0.92 & -1.49 & 0.44 & 0.93 & 21.69 \\
\hline \multirow{2}{*}{$\mathrm{R}(\mathrm{Z}, \mathrm{ZDR})$} & $S A C-S M A$ & 0.77 & 0.02 & 0.81 & 0.39 & 0.91 & 5.99 \\
\cline { 2 - 8 } & $S M A P$ & 0.68 & 0.18 & 0.53 & 0.38 & 0.84 & 9.43 \\
\hline \multirow{2}{*}{ Rdisdro } & $S A C-S M A$ & -1.47 & 2.15 & -7.06 & -2.32 & 0.71 & 38.99 \\
\cline { 2 - 8 } & $S M A P$ & -0.20 & 0.90 & -0.94 & 0.00 & 0.90 & 19.11 \\
\hline \multirow{2}{*}{ SIPREC } & $S A C-S M A$ & -1.92 & 2.19 & -9.07 & -1.78 & 0.87 & 43.61 \\
\cline { 2 - 8 } & $S M A P$ & -0.64 & 1.04 & -2.14 & 0.39 & 0,94 & 24.35 \\
\hline
\end{tabular}




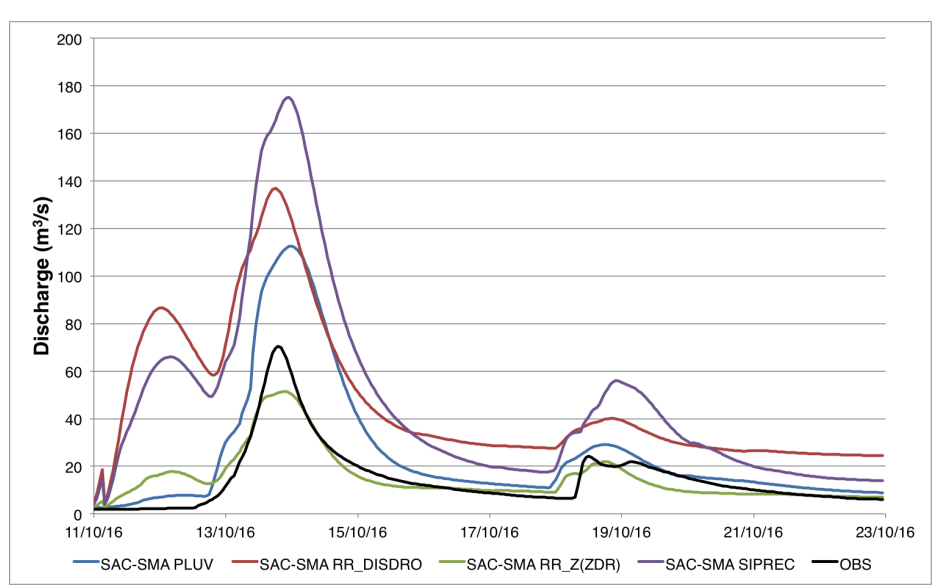

Figure 7. Simulated discharges for flood events in october 2016 with the SAC-SMA model and different QPE

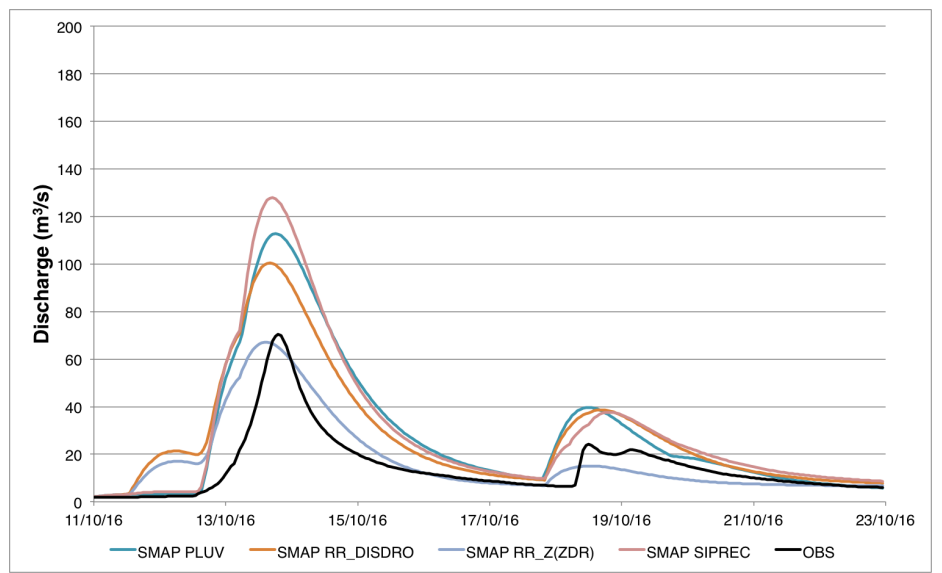

Figure 8. Simulated discharges for flood events in october 2016 with the SMAP model and different QPE

The hydrological processes in the SMAP conceptual model is less complex than the SAC-SMA and can explain, at least partially, the inter-model capabilities. The SMAP model tends to reproduce hydrogragh flashiness in smaller catchments, but it is also more sensititive to initial conditions. Since the Marrecas River has peak flows much larger than the mean discharge $\left(10 \mathrm{~m}^{3} / \mathrm{s}\right)$, the multi-objective optimization provided a good balance for both high and low flows forecasts, reproducing the hydrograph variability.

Both SAC-SMA and SMAP simulated river discharges in a realistic manner, but with no clear better estimation in radar-derived rainfall. Even if R(Z,ZDR) showed good agreement in both periods of flood events (oct/2016 and nov/2017), a more conservative approach for flood forecast and alert in the Marrecas River should consider an ensemble of these models. The successful use of rainfall retrieved from radar for rainfall-runoff modeling stresses its potential use in providing reliable rainfall and flood estimates in less-well monitored areas within its range, such as the Quatorze river.

\section{Conclusion}

In this study we evaluated rainfall-runoff models forced with radar rainfall inputs for river flood prediction. In general, simulations with SAC-SMA and SMAP indicate that tipping-bucket and radar-derived rainfall were both capable to provide reliable to flood prediction in the Marrecas river. The rainfall derived from $\mathrm{R}(\mathrm{Z}, \mathrm{ZDR})$ provided reliable simulations for the major flood events in oct/2016 and nov/2017. The prediction of catchment runoff in ungauged catchments in the region such as the Quatorze River - is most likely to benefit from the radar information. Finally, besides the 
rainfall uncertainty, flood modeling and forecast also depends of the model structure and accuracy of rating curves at high flows.

Author Contributions: Conceptualization, C. B., L. C. and R. C.; methodology, L. C., C. B., R. C. and M. S. ; software, C. O., N. R., J. B.; validation, C. B., R. C. and M. S.; writing-original draft preparation, C. B.; writing-review and editing, R. C., M. S. and L. C.; visualization, C. O.; supervision, C. B.; project administration, C. B.; funding acquisition, C. B.

Funding: This research was funded by SIMEPAR, Parana Meteorological Service, Curitiba, Brazil.

Acknowledgments: In this section you can acknowledge any support given which is not covered by the author contribution or funding sections. This may include administrative and technical support, or donations in kind (e.g., materials used for experiments).

Conflicts of Interest: The authors declare no conflict of interest. The funders had no role in the design of the study; in the collection, analyses, or interpretation of data; in the writing of the manuscript, or in the decision to publish the results.

\section{Abbreviations}

The following abbreviations are used in this manuscript:

DOAJ Directory of open access journals

\section{References}

1. Calvetti, L.; Beneti, C.; Neundorf, R.L.A.; Inouye, R.T.; dos Santos, T.N.; Gomes, A.M.; Herdies, D.L.; de Goncalves, L.G.G. Quantitative Precipitation Estimation Integrated by Poisson's Equation Using Radar Mosaic, Satellite, and Rain Gauge Network. Journal of Hydrologic Engineering 2017, 22, E5016003. doi:10.1061/(ASCE)HE.1943-5584.0001432.

2. Crisologo, I.; Vulpiani, G.; Abon, C.C.; David, C.P.C.; Bronstert, A.; Heistermann, M. Polarimetric rainfall retrieval from a C-Band weather radar in a tropical environment (The Philippines). Asia-Pacific Journal of Atmospheric Sciences 2014, 50, 595-607. doi:10.1007/s13143-014-0049-y.

3. Yapo, P.O.; Gupta, H.V.; Sorooshian, S. Multi-objective global optimization for hydrologic models. Journal of Hydrology 1998, 204, 83 - 97. doi:https://doi.org/10.1016/S0022-1694(97)00107-8.

4. Gupta, H.V.; Kling, H.; Yilmaz, K.K.; Martinez, G.F. Decomposition of the mean squared error and NSE performance criteria: Implications for improving hydrological modelling. Journal of Hydrology 2009, 377, 80 - 91. doi:https://doi.org/10.1016/j.jhydrol.2009.08.003.

5. Burnash, R.J.C., F.R.; McGuire, R. A Generalized Streamflow Simulation System Conceptual Modeling for Digital Computers. Technical report, Joint Federal-State River Forecast Center, Sacramento, CA, 1973.

6. Duan, Q.; Sorooshian, S.; Gupta, V. Effective and Efficient Global Optimization for Conceptual Rainfall-Runoff Models. Water Resources Research 1992, 28, 1015-1031.

7. Lopes J.E.G, Braga B.P.F, C.J. SMAP - A Simplified Hydrological Model. Applied Modelling in Catchment Hydrology ed. V.P.Singh, Water Resourses Publications., 1982. 